\title{
INFLUENCE OF COIMPLANTATION ON ACTIVATION OF Er EMISSION IN Si*
}

\author{
H. Przybylińska
}

Institute of Physics, Polish Academy of Sciences

Al. Lotników 32/46, 02-668 Warszawa, Poland

\section{G. Hendorfer, W. Jantsch and L. Palmetshofer}

Institut für Experimentalphysik, Johannes Kepler Universität, 4040 Linz-Auhof, Austria

The results of high resolution photoluminescence studies of erbium implanted silicon are presented. We show that the apparent enhancement of Er emission by coimplantation with light elements is not due to formation of Er-dopant complexes, but rather to Er forming complexes with defects induced by the implantation process alone.

PACS numbers: $78.55 . \mathrm{Hx}, 61.72 . \mathrm{Tt}$

The almost atomic character of the intra- $4 f$-shell emission of rare earth impurities makes them very attractive for semiconductor optoelectronic devices. Among them erbium has excited much interest, since the ${ }^{4} I_{13 / 2} \rightarrow{ }^{4} I_{15 / 2}$ transition of $\mathrm{Er}^{3+}$ occurs at $1.54 \mu \mathrm{m}$, which coincides with the minimum loss wavelength region of silica-based optical fibers $[1,2]$. One of the most studied systems with view to potential applications is silicon implanted with erbium. A considerable progress in improving the luminescence yield was obtained after detailed, though rather heuristic studies of the implantation and annealing conditions [3-6]. It was also reported that coimplantation with light elements, such as $\mathrm{C}, \mathrm{N}, \mathrm{O}$, and $\mathrm{F}$ can substantially increase the photoluminescence (PL) intensity $[5,6]$. The latter is believed to be due to the formation of Er-dopant complexes. All this resulted in the achievement of room temperature electroluminescence of the Si:Er system [7, 8], however, still almost nothing is known about the microscopic structure of the optically active erbium centers.

In this paper we present high-resolution $\mathrm{PL}$ investigations of Er-implanted Czochralski (CZ) and float-zone (FZ) grown Si, performed with the use of a Fourier

*This work is supported by Gesellschaft für Mikroelektronik (Austria) and partially supported by the grant No. 8 S501 02905 of the State Committee for Scientific Research (Republic of Poland). 
(a)

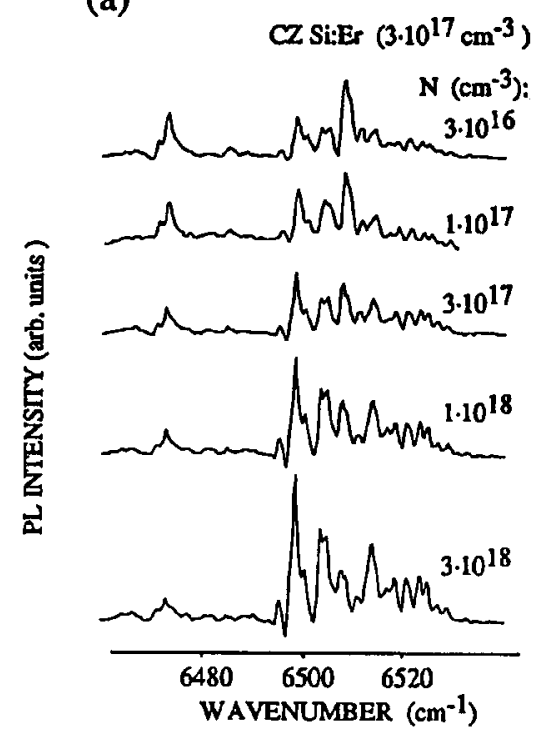

(c)

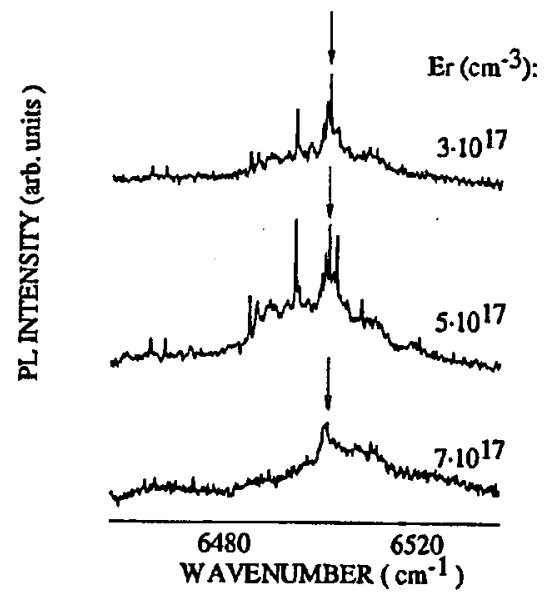

(b)

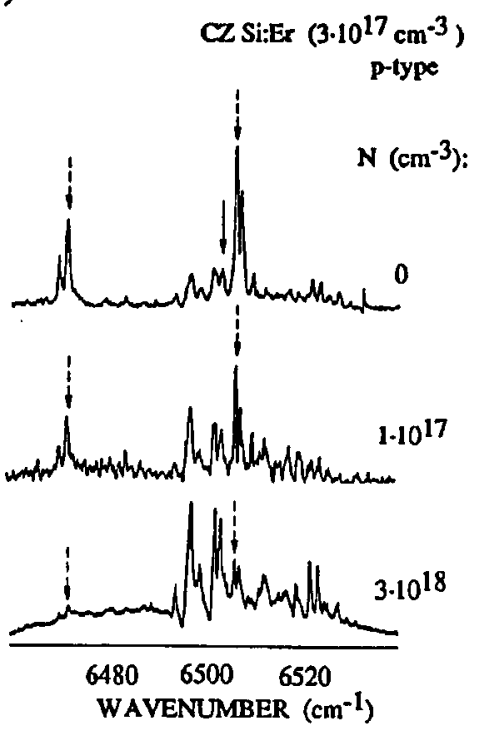

(d)

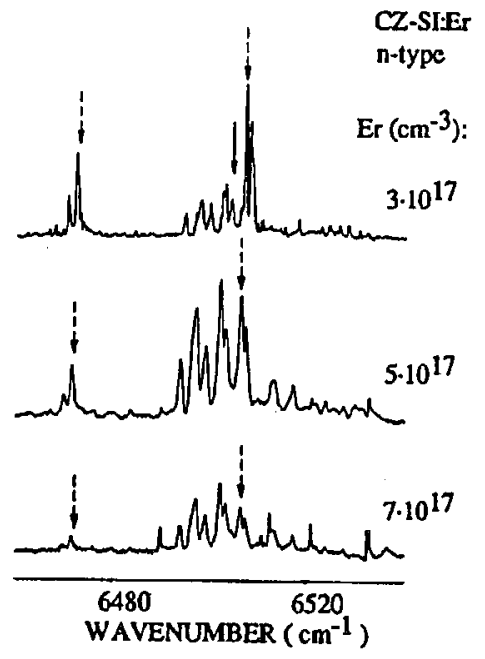

Fig. 1. PL spectra of a $p$-type CZ Si sample with Er peak concentration of $3 \times 10^{17} \mathrm{~cm}^{-3}$, coimplanted with different $N$ doses and measured with the resolution of $0.8 \mathrm{~cm}^{-1}$ (a) and $0.1 \mathrm{~cm}^{-1}$ (b) at $4.2 \mathrm{~K}$. The nitrogen peak concentrations are indicated in the figure. Below the PL spectra for three different Er concentrations are shown, implanted into $n$-type FZ Si (c) and $n$-type CZ Si (d), measured with the resolution of $0.2 \mathrm{~cm}^{-1}$. The FZ spectra are amplified with respect to others by a factor of 5 . The solid arrow indicates the transition to the lowest crystal-field split level of a cubic $\mathrm{Er}^{3+}$ center, whereas dashed arrows mark the two subsequent transitions for two erbium centers with lower than cubic site symmetry and very similar crystal-field splittings, which we relate to Er-O complexes. 
transform Bomem DA8 spectrometer. Erbium was implanted at $320 \mathrm{keV}$ to the peak concentrations of 3,5 , and $7 \times 10^{17} \mathrm{~cm}^{-3}$, the $\mathrm{N}$ implants were performed at $46 \mathrm{keV}$ to concentrations varying from $10^{16}$ to $10^{18} \mathrm{~cm}^{-3}$. The implantation damage was annealed out at $900^{\circ} \mathrm{C}$ in vacuum for $30 \mathrm{~min}$, which was reported to be the best for obtaining maximum photoluminescence signal in the $\mathrm{CZ}$ material [3-5]. All emission spectra shown in the figures were excited with the $514.5 \mathrm{~nm}$ Ar laser line and measured at $4.2 \mathrm{~K}$.

Figure 1a shows the PL spectrum of a $p$-type CZ Si sample implanted with the lowest Er dose and coimplanted with various doses of nitrogen, measured with the resolution of $0.8 \mathrm{~cm}^{-1}$. The $\mathrm{N}$ peak concentration is indicated in the figure. Figure $1 \mathrm{~b}$ depicts the same spectral region with the resolution of $0.1 \mathrm{~cm}^{-1}$ for two of the $\mathrm{N}$ coimplanted samples, as compared to the sample containing only Er. The solid arrow indicates the transition to the lowest crystal-field split level of a cubic $\mathrm{Er}^{3+}$ center (the next line is at $6426 \mathrm{~cm}^{-1}$ ), which is typically observed after annealing at $900^{\circ} \mathrm{C}$ [3-6]. We assign it to an isolated, interstitial site [9]. Dashed arrows mark the two subsequent transitions for two erbium centers with lower than cubic site symmetry and very similar crystal-field splittings, which we relate to $\mathrm{Er}-\mathrm{O}$ complexes [9]. Those lines deal as reference when comparing the PL intensity changes after nitrogen coimplantation.

It is clearly visible that the introduction of nitrogen does not lead to the appearance of any new emission lines. Instead, only a change in the relative intensities of the various PL lines is observed, which were already present before $\mathrm{N}$ coimplantation. A similar effect of concentration redistribution of the various Er sites present is achieved by increasing the Er implant dose alone, as shown in Fig. 1d. It is obvious that other emitting Er centers (apart from the cubic and O-related ones indicated with arrows) contain some implantation induced defects, not totally recovered during annealing. As most of the lines (in the depicted spectral range about 50 very narrow lines are observed) do not appear in FZ Si (see Fig. 1c) it can be deduced that the crystal surrounding is further modified by the presence of oxygen in the vicinity of the defect. The oxygen content in $\mathrm{CZ} \mathrm{Si}$ is about $10^{18} \mathrm{~cm}^{-3}$ and almost two orders of magnitude higher than in the FZ material.

Since the integrated PL intensity evidently increases with increasing $N$ concentration, it seems that the emission of implantation-defect related centers is more efficient. However, the emission of such centers increases with increasing erbium content only up to a point. At Er peak concentration of $7 \times 10^{17} \mathrm{~cm}^{-3}$ the overall PL intensity is noticeably weaker, apparently due to formation of Er precipitates [5], and possibly also to the increased number of other damage centers which can act as recombination centers for electron-hole pairs and thus reduce the efficiency of energy transfer to erbium.

\section{Acknowledgments}

One of us, H.P., thanks the University of Linz for support during a one- and a two-month stay in Linz. 


\section{References}

[1] H. Ennen, J. Schneider, G. Pomrenke, A. Axmann, Appl. Phys. Lett. 43, 943 (1983).

[2] H. Ennen, G. Pomrenke, A. Axmann, K. Eisele, W. Haydl, J. Schneider, Appl. Phys. Lett. 46, 381 (1985).

[3] Y.S. Tang, K.C. Heasman, W.P. Gillin, B.J. Sealy, Appl. Phys. Lett. 55, 432 (1989).

[4] J.L. Benton, J. Michel, L.C. Kimerling, D.C. Jacobon, Y.-H. Xie, D.J. Eaglesham, E.A. Fitzgerald, J.M. Poate, J. Appl. Phys. 70, 2667 (1991).

[5] J. Michel, J.L.Benton, R.F. Ferrante, D.C. Jacobson, D.J. Eaglesham, E.A. Fitzgerald, Y.-H. Xie, J.M. Poate, L.C. Kimerling, J. Appl. Phys. 70, 2672 (1991).

[6] J. Michel, L.C. Kimerling, J.L. Benton, D.J. Eaglesham, E.A. Fitzgerald, D.C. Jacobson, J.M. Poate, Y.H. Xie, R.F. Ferrante, Mater. Sci. Forum 83-87, 653 (1992).

[7] J. Michel, F.Y.G. Ren, B. Zheng, D.C. Jacobson, J.M. Poate, L.C. Kimerling, Mater. Sci. Forum 143-147, 707 (1993).

[8] G. Franzó, F. Priolo, S. Coffa, A. Polman, A. Carnera, Appl. Phys. Lett. 64, 2235 (1994).

[9] H. Przybylińska, J. Enzenhofer, G. Hendorfer, M. Schoisswohl, L. Palmetshofer, W. Jantsch, Mater. Sci. Forum 143-147, 715 (1993). 